\begin{tabular}{|l|c|c|c|}
\hline Eisqeitalter und Gegenwart & $\mathbf{5 5}$ & $\begin{array}{c}\text { 43-63 } \\
\text { 3 Abb., } 1 \text { Tab. }\end{array}$ & Hannover 2005 \\
\hline
\end{tabular}

\title{
Das Pleistozän des nördlichen Harzvorlands - eine Zusammenfassung
}

\author{
Hans-Jürgen Weymann, Ludger Feldmann \& Henning Bombien*
}

Keywords: quaternary, harz foreland, glaciofluvial/ fluvial deposits, terrace stratigraphy

Kurzfassung: Das nördliche Harzvorland liegt im Grenzbereich zwischen der ehemaligen nordischen Vereisung und dem Perigazialraum Mitteleuropas. Die ältesten pleistozänen Sedimente bilden Terrassenkiese, die vor der Elstereiszeit abgelagert wurden und einem nicht näher datierbaren Oberterrassensystem zugeordnet werden. Die Elstereiszeit ist durch Terrassenkies und glazifluviatile Sande überliefert. Die folgende Holstein-Warmzeit lässt sich nur an wenigen Stellen pedologisch nachweisen. Für den Saale-Komplex wird erstmals eine litho- und pedostratigraphische Gliederung für das Harzvorland vorgestellt. Die Fuhne-Kaltzeit und die DömnitzWarmzeit lassen sich anhand von Fließerden, Kaltzeitindikatoren sowie Böden belegen. Der darüber liegende Mittelterrassen-Kies der Saale-Kaltzeit stellt den wichtigsten Leithorizont im Pleistozän dar. Er lässt sich in mehrere Aufschüttungsphasen untergliedern. Darüber folgen stellenweise glazigene und glazifluviatile Sedimente. Die Entwässerung während der maximalen Ausdehnung des Eises erfolgte unter und vor dem Eis. Dieses wird durch die Anlage einer bedeutenden Talung sowie glazifluviatiler Ablagerungen belegt. Das Eis schmolz über mehrere Toteisphasen $\mathrm{ab}$.

In der letzten Kaltzeit herrschten im Harzvorland

\footnotetext{
*Anschriften der Verfasser: Dr. H.-J. Weymann, Wedekindstraße 12A, D-30161 Hannover, Email: h-j.weymann@freenet.de; PD Dr. habil. L. FeLDMANN, Merkurstraße 20, D-71726 Benningen, Email: ludger_feldmann@yahoo.de; Dr. H. BomBIEN, Dorfstraße 71, D-31637 Rodewald, Email: henningbombien@aol.com.
}

periglaziale Bedingungen, unter denen der Niederterrassen-Schotter in den bereits vorher existierenden Tälern abgelagert wurde.

Abstract: The northern Harz foreland is the borderland between the former northern glaciation and the periglacial area of Central Europe. The oldest sediments of the Pleistocene period are fluvial gravel deposited before the Elster glacial period. They can not be exactly dated and were assigned to a system called "Oberterrasse" (upper terrace).

The Elster glacial period is documented by fluvial gravel and melt water sand. The following Holstein interglacial period is verified only by a few pedological sites. The early Saale period can be divided for the first time in this area into periglacial sediments, ice wedges and soils. In the top of these layers follows the gravel of the "Mittelterrasse" (middle terrace). It is the most important layer of the Pleistocene in the Harz foreland. It can be divided into several accumulation periods. The middle terrace is covered by isolated glacial and periglacial sediments.

The drainage during the maximum expansion of the northern ice mass is showing by a great valley and melt water sand. The melt water eroded parts of the valleys under the ice parallel to the border of the glacier.

The retreat of the glaciers happened in form of dead ice periods.

In the last glacial period, the Weichsel period, the Harz foreland lay in the periglacial area. The valley, that was formed before this time under the ice mass, was filled with gravel of the "Niederterrasse" (lower terrace). 


\section{Vorwort}

Dieser Aufsatz ist Johann-Peter Groetzner gewidmet, der Anfang Oktober 2003 nach schwerer Krankheit verstorben ist.

Neben vielen anderen Projekten hat J.-P. Groetzner seit Anfang 1980 vom Institut für Geologie und Paläontologie der Universität Hannover aus eine moderne Bearbeitung der lange vernachlässigten quartärzeitlichen Ablagerungen des nördlichen Harzvorlandes vorangetrieben. Viele Diplomarbeiten und zwei Dissertationen sind zu diesem Themenbereich von ihm initiiert und betreut worden. Eine Habilitationsarbeit hat er mit fachlichem Rat begleitet. Sein persönliches Engagement ging dabei weit über die dienstliche Pflichterfüllung hinaus.

Alle, die er in dieser Zeit unter seine „Fittiche“ nahm, lernten seine in fachlichen Fragen konstruktiv-kritische Haltung zu schätzen. Dies war, vor allem als Diplomand, nicht immer leicht, da seine Anforderungen sehr hoch waren. Jeder, der bei ihm einmal eine Arbeit zur Korrekturlesung abgegeben hat, wird dies bestätigen können. Seine zum Teil sehr harte Kritik war aber nie Selbstzweck, sondern diente immer zur Verbesserung der fachlichen Qualität. Dabei haben wir von J.-P. Groetzner gelernt, dass fachlicher Streit und persönliche Beziehungen strikt voneinander $\mathrm{zu}$ trennen sind. Dies hat er uns immer vorgelebt. Die ihm eigene Verbindung von hoher fachlicher Kompetenz und menschlicher Qualität hat ihn für uns und für viele andere zu einem guten Freund werden lassen. Viele haben ihm viel zu verdanken.

\section{Einleitung}

Die pleistozänen Sedimente des nördlichen Harzvorlands waren schon zu Beginn des letzten Jahrhunderts Gegenstand der Forschung. Hierzu trugen die Bearbeiter der Preußischen Geologischen Landesanstalt von Berlin einen großen Anteil bei. Anfang 1980 begann am Institut für Geologie und Paläontologie der Universität Hannover eine Arbeitsgruppe um Groetzner auf niedersächsischer Seite, die pleistozänen Sedimente des nördlichen Harz- vorlands neu zu bearbeiten (Bombien 1983, Christofzik 1983). Zu nennen ist Bombien (1987), der nach geröllpetrographischen Untersuchungen drei frühsaalezeitliche Flusssysteme unterscheiden konnte: Innerste-, Gose- und Oker-Radau-Ecker-Ilsesystem. Nach der Wiedervereinigung konnte die Erforschung der pleistozänen Sedimente auf sachsen-anhaltinische Seite ausgedehnt werden (Groetzner \& Weymann 1998, Groetzner \& Winter 1998). Ab Mitte der 90ziger Jahre vergrößerte sich mit Feldmann (Institut für Geologie und Paläontologie der TU Clausthal) die Arbeitsgruppe (Feldmann \& Groetzner 1998, Feldmann et al. 2001). In einer zusammenfassenden Arbeit beschrieb Feldmann (2002) das Quartär zwischen Harz und Allertal und stellte die Landschaftsgeschichte des nördlichen Harzvorlandes vom Jungtertiär bis zum Holozän mit Schwerpunkt ab der Elster-Kaltzeit dar. Neben der stratigraphischen Ansprache und Deutung der Sedimente wurde eine klimatische Rekonstruktion für den betrachteten Zeitraum erarbeitet. Zuletzt gliederte Weymann (2004) im nordöstlichen Harzvorland aufgrund geröllpetrographischer Untersuchungen präelster- und frühsaalezeitliche Flusssysteme an Ecker, Ilse, Rammelsbach, Goldbach, Holtemme, Bode, Selke und Eine aus. Der vorliegende Aufsatz soll als zusammenfassende Darstellung bisheriger Arbeiten (Bombien i987, Feldmann 2002, Weymann 2004) einen Beitrag zum Quartär des nördlichen Harzvorlands leisten.

\section{Das Untersuchungsgebiet}

Das Untersuchungsgebiet umfasst das nördliche Harzvorland zwischen der Innerste im Westen und der Eine im Osten (Abb. 1). Der Harzrand bildet die Südgrenze, die markante Talung des Großen Bruchs sowie im weiteren Verlauf der Salzgitterer Höhenzug stellen die Nordbegrenzung dar. Salzgitterer Höhenzug (275 m), Gro- 


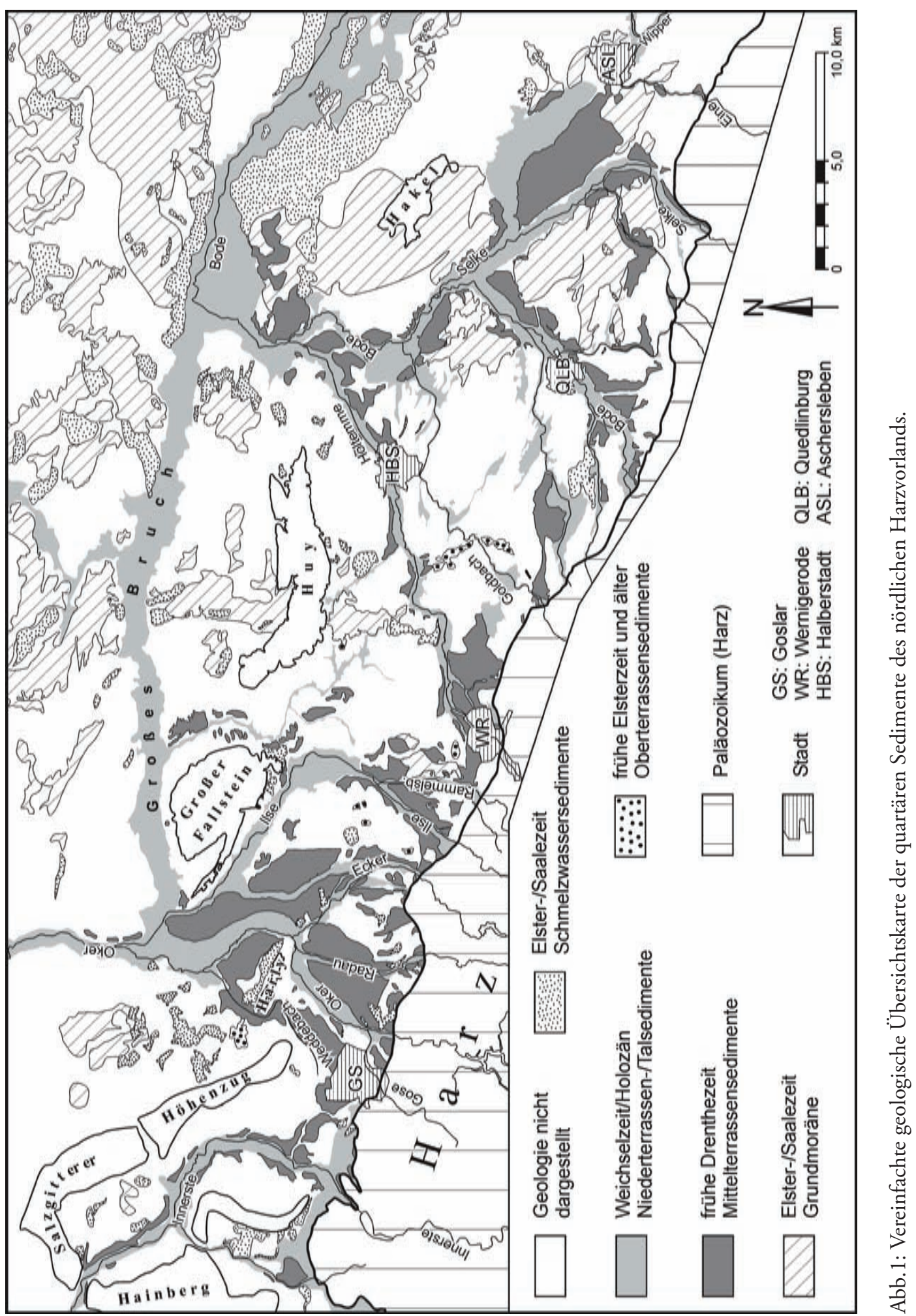


Ber Fallstein (288 m), Huy (315 m) und Hakel $(241 \mathrm{~m})$ erheben sich in der Landschaft als markante Höhenzüge. Die Innerste und Oker, die dem Wesereinzugsgebiet tributär sind, sowie die Bode, die dem Elbeeinzugsgebiet tributär ist, verlassen das Untersuchungsgebiet in nördlicher Richtung. Die Wasserscheide Weser-/Elbeeinzugsgebiet verläuft von Norden kommend quer durch das Große Bruch über den höchsten Punkt des Großen Fallsteins und im weiteren Verlauf östlich der Ilse zwischen Rammelsbach und Holtemme zum Harzrand.

Das Untersuchungsgebiet ist auf den geologischen Übersichtskarten von Look (1984), Hinze et al. (1998) und Schroeder (1930) dargestellt und liegt im südlichen Teil des subherzynen Beckens. Die mesozoischen Schichten, die z.T. von quartären Sedimenten überdeckt werden, bilden flache Mulden und Sättel und sind unmittelbar am Harznordrand steil gestellt oder überkippt. In den Mulden treten Sedimente des Keupers und Juras und im Westen der Kreide auf. Dagegen werden die an Salzstrukturen gebundenen Sättel von Gesteinen des Buntsandsteins und Muschelkalks aufgebaut. Der Südteil des Untersuchungsgebiets wird von der subherzynen Kreidemulde mit Gesteinen der Unter- und Oberkreide eingenommen. Die Kreidemulde wird lokal vom Quedlinburger Sattel mit jurasischen Schichten und vom Harly mit Gesteinen der Trias aufgebrochen. Am nördlichen Harzrand treten Schichten vom Zechstein bis zur Oberkreide auf.

Weit verbreitet sind im nördlichen Harvorland quartärzeitliche Sedimente, die vor allem in der Elster-, Saale- und Weichsel-Kaltzeit abgelagert wurden. Dagegen sind Sedimente des Altpleistozäns nur relikthaft vorhanden. Aus Skandinavien kommende Inlandgletscher der Elster- und Saale-Kaltzeit reichten bis zum Harzrand, das Elstereis überfuhr den Unterharz. Die Eigenvergletscherung des Harzes (DupHorn 1968) erreichte nirgends das Untersuchungsgebiet (Feldmann 1997). Warmzeitliche Bildungen des Holsteins und Eems sind im Untersuchungsgebiet nur an wenigen Stellen dokumentiert. Mit dem Holozän begannen warmzeitliche Prozesse, die bis heute andauern.

\section{Die pleistozänen Sedimente}

Im Untersuchungsgebiet sind Schmelzwasserund Flusssedimente die häufigsten pleistozänen Ablagerungen. Daneben treten äolische und glazigene Ablagerungen auf. Die stratigraphische und genetische Einordnung der Ablagerungen erfolgt nach verschiedenen Kriterien. Oft lassen sich im Aufschluss nach der petrographischen Zusammensetzung die sandreichen, deutlich geschichteten Schmelzwassersedimente von den undeutlich geschichteten, aus Kies und untergeordnet Sand sowie Pelit bestehenden Flusssedimente abgrenzen. Zudem lässt die Geröllführung solcher Sedimente Rückschlüsse auf ihre Genese zu. Nach geröllanalytischer Auswertung (Mittelkiesfraktion 6,3-20,0 mm, ohne Kalksteine) durch Bombien (1987) und Weymann (2004) weisen Schmelzwassersedimente neben einheimisch mesozoischen und einheimisch paläozoischen Gesteinen einen Anteil an nordischen Gesteinen von 12-75\% (Stück-\%) auf. Dagegen liegt in Flusssedimenten der nordische Anteil i.d.R. bei 0-6\%, im Gegensatz zum dominierenden paläozoischen Anteil von 90-100\%. Die paläozoische Geröllführung spielt eine wesentliche Rolle bei der Identifizierung einzelner Flusssedimente, da die oben genannten Flüsse (Kap. 1) ihre Liefergebiete im Harz haben. Hierdurch ist die Geröllführung der Ablagerungen signifikant von den in den jeweiligen Einzugsgebieten auftretenden paläozoischen Gesteinsserien geprägt.

Weiterhin stellen die Geomorphologie und die Bodenkunde im Untersuchungsgebiet für die stratigraphische Einteilung quartärer Sedimente wichtige Methoden dar. Bei der 
Geomorphologie ist die Höhenlage der Terrassen von kaltzeitlichen Flusssedimenten in Bezug zum Vorfluterniveau der zugehörigen Flüsse von Bedeutung. Entsprechend der drei nachgewiesenen Kaltzeiten können im nördlichen Harzvorland grob drei Terrassensysteme ausgegliedert werden. Hierbei weisen die ältesten Flussterrassen mit 35-70 m über Vorfluterniveau die größten Höhendifferenzen auf. Deren Ablagerungen werden einem präbis frühelsterzeitlichen Oberterrassensystem zugeordnet. Die Mittelterrasse liegt i.d.R. 15-20 $\mathrm{m}$ über Vorfluterniveau. Deren Flusssedimente werden als überwiegend frühdrenthezeitliche Mittelterrassensedimente gedeutet, die aber durchaus auch spätelsterzeitliche Anteile haben können (Tab. 1). Im Gegensatz zu den Ablagerungen des Oberterrassensystems enthalten mittelterrassenzeitliche Sedimente in der Regel einen geringen nordischen Geröllanteil. Die Niederterrassensedimente liegen $0-1 \mathrm{~m}$ über Vorfluterniveau. Sie werden in die WeichselKaltzeit gestellt. Ein weiteres stratigraphisches Hilfsmittel sind warmzeitliche Böden, die im Untersuchungsgebiet z.T. als Parabraunerden oder in Form von Entkalkungshorizonten vorliegen. Sie sind aus der Holstein- und EemWarmzeit überliefert. Der Saale-Komplex lässt sich im nördlichen Harzvorland bodenkundlich in die Fuhne-Kaltzeit, die anschließende Schöningen- bzw. Dömnitz-Warmzeit und das darauffolgende kaltzeitliche Drenthe-Stadium differenzieren (Tab. 1).

\subsection{Prä-Elster- bis frühe Elster-Kaltzeit}

Präglaziale bzw. präelsterzeitliche Ablagerungen sind im nördlichen Harzvorland aufgrund der erosiven Wirkung der elster- und saalezeitlichen nordischen Inlandgletscher selten $\mathrm{zu}$ finden (Abb. 1). An verschiedenen Stellen sind isolierte präglaziale Kiesvorkommen beschrieben, die z.T. deutlich über dem Niveau der Mittelterrasse liegen. Diese Vorkommen finden sich als Kiesstreu auf der Geländeoberfläche und bestehen aus kantengerundetem, paläozoischen Geröllmaterial. Sie werden einem nicht näher datierbaren Oberterrassensystem zugeordnet, dessen Entstehungszeit vom Altpleistozän bis in die frühe Elster-Kaltzeit reicht (Tab. 1). Auf niedersächsischer Seite ist ein solches Vorkommen mit $35 \mathrm{~m}$ über dem nächstgelegenen Mittelterrassen-Vorkommen am Oheberg (früher Ohmberg) bei Klein Döhren erhalten (Bode \& Schroeder 1926, Bombien 1987, WeIsSERMel 1930). In seiner paläozoischen Geröllführung stimmt dieser Kies fast völlig mit Ablagerungen der Gose-Mittelterrasse überein und wird von Bombien (1987) als Ablagerung einer „Ur-Gose“ gedeutet. Weitere 75 Oberterrassen-Vorkommen beschrieb SpreITZER (1931) im Bereich der Innerste. Allerdings konnten an keinem dieser Vorkommen nach Überprüfung durch Rausch (1977) präglaziale Flusssedimente nachgewiesen werden. Preul (1968) beschreibt aus Bohrungen im Bereich des Subrosionsgebietes bei Salzgitter-Lebenstedt Oberterrassensediment-Vorkommen der Innerste. Nach Spreitzer (1931) soll es sich um Ablagerungen der Nette handeln, da die Innerste zu dieser Zeit einen nördlichen Lauf über Liebenburg und Salzgitter Bad besaß (Abb. 2). Erst ab der Elster-Kaltzeit wurde der Bereich bei Salzgitter-Lebenstedt von der Innerste eingenommen (Spreitzer I93 I, Bombien i987). Auf sachsen-anhaltinischer Seite sind weitere Oberterrassensediment-Vorkommen zu finden, die sich auf das Gebiet zwischen Radau und Ilse konzentrieren (Hinze 1998, Schroeder 1930, Weissermel 1930, Weissermel et al. 1932, Weymann 2004). Viele dieser Vorkommen konnten nach Geländebegehungen nicht als Oberterrassensedimente identifiziert werden, sondern es handelten sich dabei entweder um Fließerden oder aufgrund der Höhenlage über Vorfluterniveau um Mittelterrassensedimente 
Tab. 1: Vereinfachte Gliederung des Quartärs im Harzvorland.

\begin{tabular}{|c|c|c|c|c|c|c|}
\hline \multicolumn{5}{|c|}{ Gliederung im nordichen Harzvorland } & $\begin{array}{c}\text { Vorgänge im nördlichen } \\
\text { Harzvorland }\end{array}$ & Produkte \\
\hline \multicolumn{5}{|c|}{$\begin{array}{llllllll} & \mathbf{H} & \mathbf{0} & \mathbf{l} & \mathbf{o} & \mathbf{z} & \mathbf{a} & \mathbf{n}\end{array}$} & $\begin{array}{l}\text { Umlagerung der Sedimente } \\
\text { durch Flüsse }\end{array}$ & Auelehm, Sand und Kies \\
\hline \multirow{2}{*}{\multicolumn{2}{|c|}{ 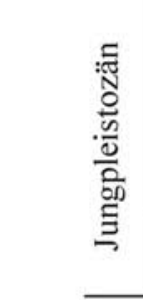 }} & \multicolumn{2}{|c|}{ Weichsel- Kaltzeit } & 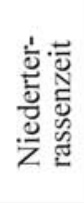 & $\begin{array}{l}\text { Periglazialbedingungen } \\
\text { Permafrostbedingungen } \\
\text { Aufschotterung in } \\
\text { Flußtälern }\end{array}$ & $\begin{array}{l}\text { Löß, Flugsand } \\
\text { Frostbodenerscheinungen } \\
\text { u.a. Eiskeile, Fließerde } \\
\text { Niederterrassensedimente }\end{array}$ \\
\hline & & \multicolumn{2}{|c|}{ Eem-Warmzeit } & & Bodenbildung & $\begin{array}{l}\text { fossile Böden } \\
\text { (Isingerode) }\end{array}$ \\
\hline \multirow{9}{*}{$\begin{array}{l}= \\
: 0 \\
N \\
0 \\
- \\
\text { n } \\
= \\
0 \\
- \\
\end{array}$} & \multirow{8}{*}{ 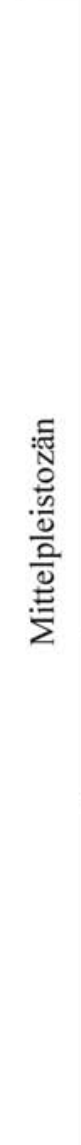 } & \multirow{4}{*}{$\begin{array}{l}\text { Saale- } \\
\text { Komplex }\end{array}$} & $\begin{array}{l}\text { Warthe- } \\
\text { Stadium }\end{array}$ & & Aufschotterung in Flußtälern & $\begin{array}{l}\text { Zwischenterrassensedimente } \\
\text { (Oker- und Eckertal) }\end{array}$ \\
\hline & & & $\begin{array}{l}\text { Drenthe- } \\
\text { Stadium }\end{array}$ & & $\begin{array}{c}\text { ?Herausbildung des } \\
\text { heutigen Flußnetzes } \\
\text { Inlandvereisung } \\
\text { Drenthe 2=Leipziger Phase } \\
\text { Hauptdrenthe=Zeitzer Phase } \\
\text { Permafrostbedingungen } \\
\text { Aufschotterung in Flußtälern }\end{array}$ & $\begin{array}{l}\text { Urstromtalsedimente } \\
\text { (Großes Bruch) } \\
\text { Grundmoräne und } \\
\text { Schmelzwassersedimente } \\
\text { Frostbodenerscheinungen } \\
\text { Mittelterrassensedimente }\end{array}$ \\
\hline & & & $\begin{array}{l}\text { Dömnitz- } \\
\text { Warmzeit }\end{array}$ & \multirow{2}{*}{ 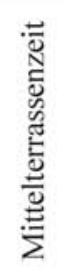 } & Bodenbildung & $\begin{array}{l}\text { fossile Böden } \\
\text { (Beuchte) }\end{array}$ \\
\hline & & & $\begin{array}{l}\text { Fuhne- } \\
\text { Kaltzeit }\end{array}$ & & Permafrostbedingungen & Fließerden, Eiskeile \\
\hline & & \multicolumn{2}{|c|}{ Holstein-Warmzeit } & & $\begin{array}{c}\text { Verwitterung } \\
\text { Auffüllung kleiner Seen u. Becken }\end{array}$ & $\begin{array}{c}\text { Entkalkungshorizonte, } \\
\text { Travertin (Schwanebeck) } \\
\text { humoser Schluff (Aschers- } \\
\text { leben, nördlich Sudmerberg) }\end{array}$ \\
\hline & & \multirow{3}{*}{\multicolumn{2}{|c|}{ Elster-Kaltzeit }} & 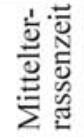 & $\begin{array}{l}\text { Herausbildung der mittelter- } \\
\text { rassenzeitlichen Flußtäler }\end{array}$ & ?Mittelterrassensedimente \\
\hline & & & & & Inlandvereisung & Schmelzwassersedimente \\
\hline & & & & 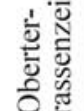 & $\begin{array}{c}\text { Permafrostbedingungen } \\
\text { Aufschotterung in Flußtälern }\end{array}$ & $\begin{array}{l}\text { Oberterrassensedimente } \\
\text { (Oberterrassensystem) }\end{array}$ \\
\hline & & \multicolumn{2}{|c|}{ Altpleistozän } & $\underset{\sim}{\downarrow}$ & $\begin{array}{c}\text { Komplex } \\
\text { Flußablagerungen in Kaltzeiten } \\
\text { Permafrost } \\
\text { Verwitterung inWarmzeiten }\end{array}$ & $\begin{array}{c}\text { ?Flußsedimente } \\
\text { (Oberterrassensystem) } \\
\text { Sudmerberg-Fauna }\end{array}$ \\
\hline
\end{tabular}




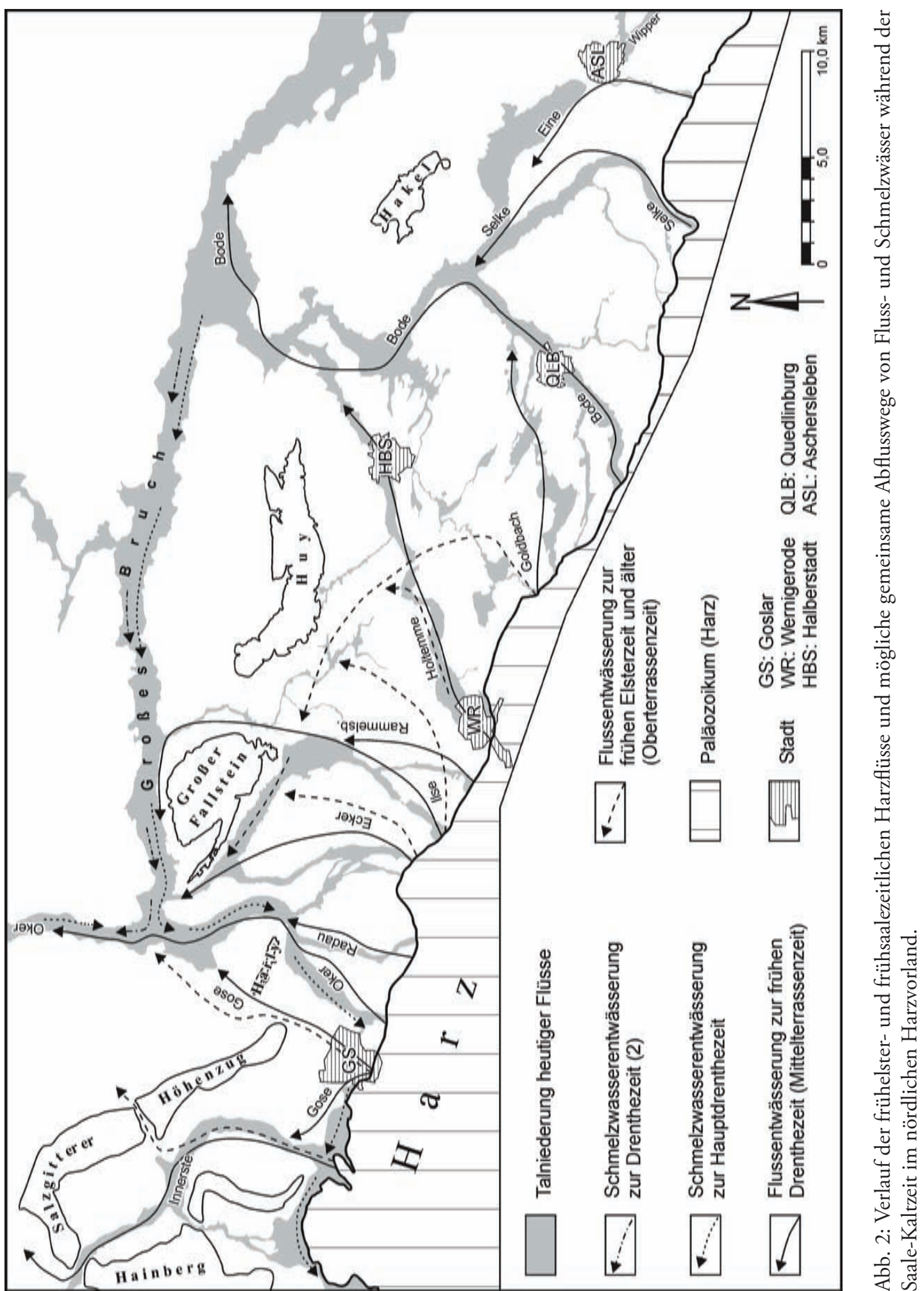


(Feldmann 2002, Weymann 2004). Ein markantes Oberterrassensediment-Vorkommen ist am Saßberg erhalten, das nach seinem paläozoischen Geröllinhalt zum Eckereinzugsgebiet gehört (WeYMann 2004). Weitere Oberterrassensediment-Vorkommen liegen am Südrand des Großen Fallsteins und können nach ihrem Geröllinhalt dem Holtemme-Goldbachsystem zugeordnet werden (Weymann 2004). Ähnliche Vorkommen sind südlich des Huys und südwestlich von Halberstadt zu finden. Nach diesen Vorkommen lässt sich ein präelsterzeitliches Holtemme-Goldbachsystem mit einem Verlauf nach Nordwesten südlich des Huys und Großen Fallsteins vermuten. Im Bereich Huy und Großer Fallstein flossen die Ilse und Ecker tributär diesem System zu (Weymann 2004). Im Ecker- und Ilsegebiet rekonstruierte Feldmann (2002) zwei Oberterrassenniveaus. Er unterteilte diese nach ihrer Höhenlage zum Vorfluterniveau mit 55-75 $\mathrm{m}$ in das obere Saßberg-Niveau und mit $35-45 \mathrm{~m}$ in das untere Stapelburg-Niveau. Nach Feldmann (2002) könnte aufgrund der Terrassenstratigraphie das Saßberg-Niveau cromer- und das StapelburgNiveau elsterzeitlich eingestuft werden.

Sehr selten treten warmzeitliche, präglaziale Ablagerungen auf. Ein solches Vorkommen beschreiben von KoENigswald (1972) und von Koenigswald \& Heinrich (1998) aus einer Spaltenfüllung am Sudmerberg bei Goslar und stufen es in den Cromer-Komplex ein.

\subsection{Elstervereisung}

Nach DAhlgrün (1929), LÜTtig (1954) und Spreitzer (1931) reichte der elsterzeitliche Inlandgletscher bis an den Nordrand des Oberharzes heran und überschritt den Unterharz (Grupe 1921). Der Ablauf der Elstervereisung ist im Untersuchungsraum nahezu unbekannt, so auch das Entwässerungsnetz der Schmelz- wässer. Wie in Ostdeutschland (EIssmanN 1975, 1994) sind auch im nordöstlichen Harzvorland an wenigen Stellen zwei elsterzeitliche Eisvorstöße erkennbar. Aus Bohrungen im Bereich der Salzstruktur Oschersleben - Staßfurt werden von Wagenbreth (1970) an Bohrprofilen zwei Grundmoränen, die durch Bändertone unterteilt werden, beschrieben. In den Tagebauen Nachterstedt und Königsaue nördlich von Aschersleben unterscheidet $\mathrm{MA}$ NIA (1967) zwei Elster-Grundmoränen durch ihren Geschiebestand.

Elsterzeitliche glaziäre Ablagerungen sind im Untersuchungsgebiet in Tagesaufschlüssen oft als Schmelzwassersedimente, selten als Beckenablagerungen oder Grundmoränen zu finden. Solche Vorkommen liegen westlich der Oker bei Wehre und Beuchte (Bombien 1987, FeldManN 2002) sowie östlich der Ilse bei Deersheim. Weitere Vorkommen sind im Bereich der Bode nördlich von Quedlinburg und im Bereich der Selke rund um Aschersleben vorhanden (Weymann 2004). All diese Vorkommen weisen im Untersuchungsgebiet den höchsten nordischen Geröllanteil von 60-75\% auf (ВомBIEN 1987). Diese Ablagerungen können sicher der Elster-Kaltzeit zugeordnet werden, da sie von Mittelterrassensedimenten überlagert werden. Zusätzlich wurde in den Aufschlüssen bei Wehre (Feldmann 2002) und westlich von Aschersleben (Groetzner \& Winter 1998) von K.-D. Meyer eine Leitgeschiebezählung durchgeführt. Die Zählung ergab nach dem TGZ eine Geschiebevormacht aus Südschweden, wie es für elsterzeitliche Sedimente in diesem Raum typisch ist (Hoffmann \& Meyer 1997). Die elsterzeitlichen Schmelzwassersedimente bei Beuchte und Wehre füllen nördlich des Harly eine Rinne unterhalb des Mittelterrassenkies (Feldmann 2002). Dieser in der Elster-Kaltzeit subglaziär angelegten Rinne folgt heute der Weddebach. Die WeddebachtalRinne wird als die südliche Fortsetzung der unteren Okertal-Rinne angesehen und gibt einen 
Hinweis auf einen Entwässerungsweg für das Schmelzwasser. Die Annahme für die elsterzeitliche Rinnen-Anlage wird durch Beobachtungen gestützt, die von Traupe (1990) aus dem Bereich Salzgitter beschrieben werden. Unter und über mächtigen Schmelzwassersedimenten lässt sich jeweils eine Grundmoräne nachweisen. Die liegende Grundmoräne kann damit als elsterzeitlich gedeutet werden.

\subsection{Holstein-Warmzeit}

Organogene oder fossilführende Sedimente, die aufgrund ihrer Biostratigraphie eindeutig der Holstein-Warmzeit zugeordnet werden können, sind im Untersuchungsgebiet nicht nachgewiesen. Auch pollenanalytisch datierte Sedimente, wie etwa im Tagebau Schöningen (URBAN 1991), sind nur aus einer Bohrung bei Seesen bekannt (Duphorn 1976). Bombien (1987) wies nördlich des Sudmerberges bei Goslar ein Holstein-Vorkommen nach. Das Vorkommen besteht aus warmzeitlichem, humosen Schluff, der von Mittelterrassensedimenten überlagert wird. Bei Aschersleben wurde von Mania (1967) ein ähnliches Vorkommen von Mudden mit warmzeitlichen Mollusken, Ostrakoden und Großsäugerknochen in die Holsteinzeit datiert, da diese ebenfalls von Mittelterrassensedimenten überlagert werden. Ein sicheres Holstein-Vorkommen stellen die molluskenführenden Travertine bei Schwanebeck östlich des Huys dar, die von glazigenen Sedimenten unter- und überlagert werden (SCHroeder 1919, WeIsSEMEL 1930).

Weitere Hinweise auf warmzeitliche Bildungen zeigen sich in Form von Entkalkungshorizonten, die als $\mathrm{Cv}$-Horizonte des ehemaligen Holsteinbodens gedeutet werden können. Ein solches Vorkommen ist im Aufschluss bei Wehre erhalten, wo der obere Bereich der elsterzeitlichen Schmelzwassersedimente einen
Entkalkungshorizont aufweist (BomBien 1987, Feldmann 2002). Ebenso kann die mächtige, entkalkte Abfolge von Schmelzwassersedimenten im Aufschluss bei Beuchte auf diese Bodenbildung zurückgeführt werden (FELDMANN 2002). Aufgrund der Mächtigkeit dieser entkalkten Abfolge scheidet eine Pedogenese unter periglazialen Permafrostbedingungen aus, so dass diese durch die Lage zwischen Elster- und Mittelterrassensedimenten in die Holstein-Warmzeit zu stellen ist. Ein weiteres Vorkommen warmzeitlicher Bildungen liegt nördlich von Legende, wo in Mittelterrassensedimenten eine bis zu $15 \mathrm{~m}$ mächtige, glazitektonisch eingeschuppte Kies-Schluff-Schicht aufgeschlossen war. Diese Schicht weist an einer Stelle umgelagertes Bt-Material einer warmzeitlichen Parabraunerde auf (Feldmann 2002). Aufgrund der Lagebeziehung zu den Mittelterrassensedimenten ist das umgelagerte Bodenmaterial prädrenthezeitlich und kann somit aus der Holstein-Warmzeit oder auch dem frühen Saale-Komplex stammen.

\subsection{Saale-Komplex}

Im nördlichen Harzvorland konnten die Ablagerungen des Saale-Komplexes am besten untersucht werden, da diese am weitesten verbreitet sind und zudem gut aufgeschlossen sind bzw. waren. Die stratigraphische Abfolge dieser Ablagerungen spiegelt einen differenzierten Wechsel an warm- und kaltzeitlichen Klimabedingungen während des Saale-Komplexes wider.

\subsubsection{Fuhne-Kaltzeit bis Dömnitz-Warmzeit}

Hinweise für Bildungen der Fuhne-Kaltzeit und Dömnitz-Warmzeit, die zwischen elsterzeitlichen Schmelzwasser- und frühdrenthezeitlichen Mittelterrassensedimenten lagern, sind im 


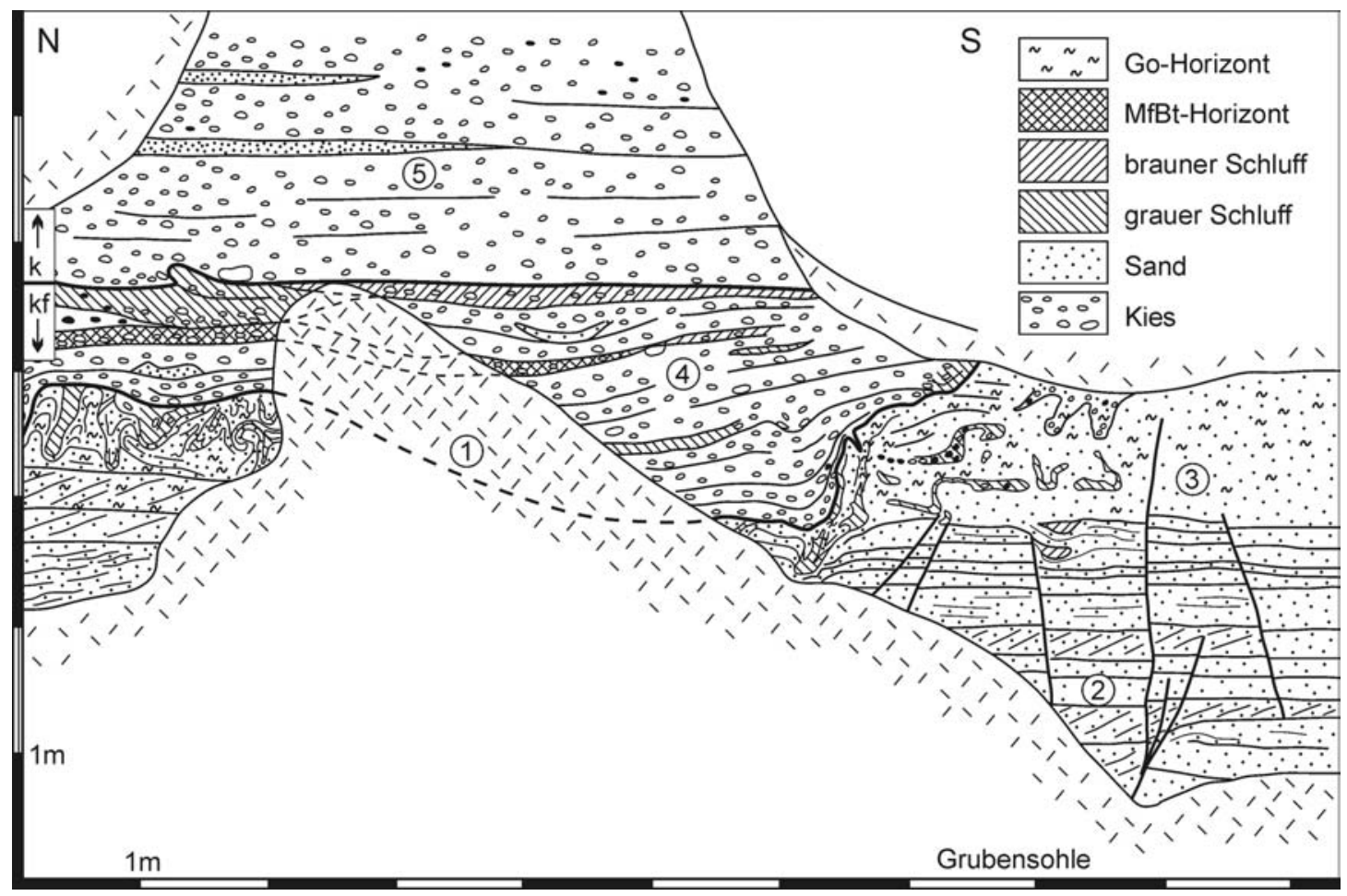

Abb. 3: Deckschichten zwischen elsterzeitlichem Schmelzwassersand und Mittelterrassenkies in Beuchte. 1) Schuttfuß, 2) geschichteter Sand, 3) entschichteter Sand, 4) Kies-Schlufflagen (kf=karbonatfrei), 5) Mittelterrassenkies ( $\mathrm{k}=$ karbonathaltig)

Untersuchungsgebiet nur aus dem Aufschluss bei Beuchte bekannt (Abb. 3). Nach FeldMANN (2002) weist die hier zwischengeschaltete Schichtenfolge zwei periglaziale Phasen in Form von entschichtetem, kryoturbat überprägten Sand (Nr. 3 in Abb. 3) und einer überlagernden Fließerde (Nr. 4 in Abb. 3) auf. In der Fließerde deuten Toncutane auf umgelagertes Bt-Bodenmaterial hin, die einer Bodenbildung der Dömnitz-Warmzeit angehören können.

Hieraus ergibt sich folgende Abfolge: Unter der Schichtenfolge lagern elsterzeitliche Schmelzwassersedimente, die im oberen Bereich in der Holstein-Warmzeit entkalkt wurden (Abb. 3; Kap. 3.3). Darüber folgt entschichteter, kryoturbat überprägter Sand. Die Überprägung wird in die Fuhne-Kaltzeit gestellt. In der darauffolgenden Dömnitz-Warmzeit bildete sich eine Parabraunerde, die in Resten als umgela- gertes Bt-Bodenmaterial erhalten blieb. Im frühen Drenthe-Stadium wurde die Parabraunerde unter periglaziären Bedingungen erodiert und als Resediment in der Fließerde abgelagert. Die gesamte Schichtenfolge wird von Mittelterrassensedimenten überlagert.

\subsubsection{Frühes Drenthe-Stadium}

Das frühe Drenthe-Stadium war im Vorfeld der Hauptvereisung durch Permafrostbedingungen geprägt (Feldmann 2002). In dieser Zeit erfolgte im nördlichen Harzvorland weitflächig in verflochtenen Flusssystemen (braided river) die Hauptakkumulation der Mittelterrassensedimente (Abb. 1; vgl. Bombien 1987, WeymanN 2004). In den Mittelterrassensedimenten sind 
vielerorts Eiskeile und Kryoturbationshorizonte eingeschaltet, die periglaziale Bedingungen während der Ablagerung belegen. In der Vergangenheit wurde insbesondere im Bereich der Bode, Selke und Eine eine Zweiteilung der Mittelterrassensedimente diskutiert, die aufgrund unterschiedlicher Geröllzusammensetzungen (Weissermel 1926, 1930), einer eingeschalteten Grundmoräne (Mania 1967) und eines Kryoturbationshorizontes (LUdwIG 1958) unterteilt waren.

Nach geröllanalytischen Untersuchungen von Weymann (2004) war in diesem Bereich eine Unterteilung dieser Sedimente nicht reproduzierbar. Im Einegebiet traten in einem Aufschluss südlich von Aschersleben in den Mittelterrassensedimenten eine eingeschaltete Schluff-Kiesschicht mit einer darunterliegenden geringmächtigen Grobkieslage aus nordischen Geröllen auf. Die Schluff-Kiesschicht wurde nach Weymann (2004) aufgrund geröllpetrographischer Zusammensetzung als Fließerde angesprochen. Die darunterliegende Grobkieslage wies nach ihrer Dachziegellagerung auf eine Fließrichtung nach Norden hin. Daher wurden die nordischen Gerölle als Resediment einer südlich gelegenen, präexistierenden elsterzeitlichen Grundmoräne gedeutet. In dem selben Aufschluss war als weitere Ausnahme ein markanter Kryoturbationshorizont erhalten. Dagegen verteilen sich im nordöstlichen Harzvorland die Kryoturbationen im Vertikalbereich der Mittelterrassensedimente i.d.R. als unregelmäßige, lateral begrenzte Bildungen. Daher wurde der im Aufschluss beobachtete Kryoturbationshorizont von WeYMAnN (2004) als lokale Erscheinung angesehen, die eine kurzfristige, mehrphasige Aufschotterung eines kaltzeitlichen Flusses (braided river) widerspiegeln. Dagegen interpretierte Feldmann (2002) im Bereich zwischen Oker und Ecker in verschiedenen Vorkommen aufgrund von Kryoturbationshorizonten und Einschaltungen von Hochflutlehm eine Zwei- bis Dreiteilung der Mittel- terrassensedimente. Er stellt aber die gesamte Gliederung der Mittelterrassensedimente in das frühe Drenthe-Stadium, was nach KNOTH (1964, 1995) für das Saalegebiet und nördliche Harzvorland der "3. Mittelterrasse" entspricht. Somit lassen sich die Mittelterrassensedimente fast ausschließlich als frühdrenthezeitliche Ablagerung deuten, die z.T. flussdynamisch in Kalt- und Warmphasen mit stadialem und interstadialem Charakter gegliedert werden können. Nur in einem Vorkommen bei Abbenrode weist der untere Teil der Mittelterrassensedimente eine Entkalkung auf, die möglicherweise auf die Holstein-Warmzeit zurückgeführt werden kann. In diesem Fall wäre der untere Teil der Mittelterrassensedimente in die späte Elster-Kaltzeit zu stellen.

Eine sichere stratigraphische Einstufung der Mittelterrassensedimente in die frühe SaaleKaltzeit erfolgte neben der teilweisen Unterund Überlagerung von Schmelzwassersedimenten durch ihre markante Höhenlage über Vorfluterniveau. Diese liegt im Bereich der Innerste und Radau bei 15 m (Bombien 1987) sowie im Bereich der Holtemme, Bode, Selke und Eine bei 15-20 m (Weymann 2004). Dagegen besitzen die Mittelterrassen im Ecker- und Ilsegebiet insbesondere im Bereich des Großen Fallsteins eine Höhe bis $25 \mathrm{~m}$ (Feldmann 2002, Weymann 2004). Für eine Deutung dieser Vorkommen als Mittelterrassensedimente spricht das geringe Auftreten nordischer Gerölle. Eine weitere Erklärung für die markant große Höhenlage im Bereich des Großen Fallsteins erfolgt im Kapitel 4.

Für die Rekonstruktion des frühdrenthezeitlichen Flussnetzes konnten im Untersuchungsgebiet die Mittelterrassensedimente nach ihrer paläozoischen Geröllführung zu den Liefergebieten heutiger Harzflüsse zugeordnet werden. Hierbei sind die Mittelterrassensedimente teilweise durch einzelne markante Gerölle ("Leitgerölle") oder spezifische Geröllspektren gekennzeichnet. Bombien (1987) konnte auf 
niedersächsischer Seite drei Flusssysteme unterscheiden. Das Innerstesystem, das nach dem Geröllbestand überwiegend aus Grauwacken-, Kieselschiefer- und Tonschiefergeröllen besteht, hatte bis zum Salzgitterer Höhenzug einen ähnlichen Verlauf wie heute (Abb. 2). Ab der Talenge zwischen Salzgitterer Höhenzug und Hainberg erfolgte der Abfluss in nordöstlicher Richtung und nicht wie heute zur Leine. In diesem Bereich sind Innerstesedimente bereits seit Woldstedt (1928) bekannt. Das Gosesystem, das nach dem Geröllbestand überwiegend durch devonzeitliche Sandstein-/Quarzitgerölle charakterisiert ist, besaß zur Mittelterrassenzeit gegenüber heute zwei unterschiedliche Abflüsse: Einen über Goslar-Jerstedt nach Westen zum Innerstesystem und einen über Immenrode-Weddingen nach Nordosten zum Okersystem. Allerdings vertreten Bombien (1987) und Feldmann (2002) eine unterschiedliche Auffassung über den zeitlichen Ablauf beider Abflusswege, so dass unklar bleibt, welcher der beiden Abflüsse der jüngere ist.

Das von Bombien (1987) bezeichnete Ostsystem, das die Oker, Radau, Ecker und Ilse umfasst, konnte von ihm aufgrund der damaligen Grenze zur DDR nur bedingt untersucht werden. Bombien (1987) beschrieb ab dem Harly einen gemeinsamen Abfluss der Oker-Radau nach Norden. Er ließ aber schon die Möglichkeit offen, dass die Ecker erst ab dem Großen Fallstein in das Ostsystem mündete. Ebenso zeichnete er schon einen Ilselauf nördlich des Großen Fallsteins nach. Weymann (2004) konnte aufgrund differenzierter Untersuchungen die Flussläufe der Ecker und Ilse rekonstruieren (Abb. 2). Das Eckersystem, das insbesondere durch Eckergneisgerölle gekennzeichnet ist, besaß gegenüber heute einen nordöstlicheren Verlauf und mündete am Nordwestrand des Großen Fallsteins in das Große Bruch. Die Ilse mit ihrem hohen Geröllanteil an Ilsesteingranit und Ackerbruchbergquarzit besaß harzrandnah eine östlichere Ausdehnung und der
Rammelsbachzufluss, gekennzeichnet durch hohen Kieselschieferanteil, lag weiter stromab. Flussabwärts floss das Ilse-Rammelsbachsystem zwischen Großem Fallstein und Huy und dann nördlich des Großen Fallsteins im Bereich des Großen Bruchs nach Westen.

Weiter im Osten floss nach Weymann (2004) der Goldbach (hohe Diabasanteile) ab dem Harzrand nach Nordosten nördlich von Quedlinburg der Bode zu. Die Bode, die durch den Zweiglimmergranit des Rambergmassivs charakterisiert ist, besaß im Bereich der heutigen Holtemmemündung eine westlichere Ausdehnung. Im Bereich von Oschersleben floss die Bode wie heute nach Osten zur Saale. Die Selke (hohe Grauwackenanteile) vereinigte sich westlich von Aschersleben mit der Eine (hohe Harzgangquarzanteile) als Selke-Einesystem und floss nach Nordwesten der Bode zu. Ein möglicher Wipperabfluss ab Aschersleben wurde aufgrund fehlender Karpholithgerölle ausgeschlossen.

\subsubsection{Drenthevereisung}

Glazigene Ablagerungen, die Mittelterrassensedimente überlagern, können dem Saale-Komplex zugeordnet werden. Solche Vorkommen sind vielerorts im Untersuchungsgebiet vorhanden. Vereinzelt liegen sie auch in unmittelbarer Nähe des Harzrandes (Bombien 1983, Christofzik 1983). Hierzu zählt insbesondere das Vorkommen bei der Innerste-Talsperre (Bombien 1987, Feldmann 2002), wo Staubecken- und Schmelzwassersedimente sowie Reste von Geschiebelehm Mittelterrassensedimente überlagern. Weitere Vorkommen lassen sich im östlichen Teil des Untersuchungsgebiets im Bereich der Bode und Selke finden, wie z.B. das Grundmoränen-Vorkommen bei Warnstedt unmittelbar nördlich des Harzrandes (WeYMANN 2004). Nach diesen lokal auftretenden 
Fundpunkten scheint ein saalezeitlicher Eisvorstoß bis in Harzrandnähe belegbar zu sein (Feldmann 2002). Dieser Eisvorstoß wird in die Hauptdrenthezeit gestellt und entspricht nach Feldmann (2002) der Zeitzer Phase bzw. nach Lüttig (1958) der Hamelner Phase. Dagegen reichte der Inlandgletscher im Drenthe 2 bis zum Allertal (Feldmann 2002) und das warthestadiale Eis bis zur Lüneburger Heide (Lüttig 1964, Höfle 1991). In einem Vorkommen bei Großalsleben wurde für den hauptdrenthezeitlichen Inlandgletscher nach Geschiebelängsachseneinregelung eine Eisvorstoßrichtung aus Nordwest ermittelt (GROETZNER \& Weymann 1998). Ein ähnlicher Wert ergab sich auch im Vorkommen bei Abbenrode (Feldmann 2002). Bombien (1987) kommt bei seinen Untersuchungen auf einen Eisvorstoß aus nordöstlicher Richtung. Beim Vorkommen bei Hoym westlich Aschersleben wurden Werte aus Ost ermittelt (GroetzNer \& Winter 1998). Die unterschiedlichen Eisvorstoßrichtungen können an einigen Stellen durch die Morphologie beeinflusst worden sein (Bombien 1987, Feldmann 2002).

Angaben zur Mindestmächtigkeit des nordischen Inlandgletschers sind unsicher. Im nördlichen Harzvorland gibt es vereinzelt Hinweise, dass die Eisoberfläche höher als 300 m ü. NN gelegen hat. Hierzu zählen die 280 $m$ ü. NN hoch gelegenen "Gletschertöpfe" im Huy (Steiner 1957, Groetzner 1998). Zu ähnlichen Ergebnissen kam auch KaLtwang (1992), der im Raum Seesen-Goslar die Höhe der Geschiebegrenzen mit 290-320 m ü. NN angibt. Allerdings ist die stratigraphische Deutung der "Gletschertöpfe" und Geschiebegrenze im Einzelnen unklar. Feldmann (2002) gibt aufgrund dieser und ähnlicher Hinweise eine Abschätzung für Eismächtigkeiten an:

- am Harzrand 50-70 m

- in $10 \mathrm{~km}$ Entfernung 160-180 m

- in $15 \mathrm{~km}$ Entfernung über $200 \mathrm{~m}$

Bis heute ist völlig ungelärt, wie das Entwäs- serungsnetz der Schmelz- und Flusswässer während der maximalen Vergletscherungsphase aussah. Feldmann (2002) kommt nach grober Abschätzung der anfallenden Schmelz- und Flusswässer auf enorme Wassermengen, die am Eisrand in der Dimension eines mittleren bis großen europäischen Flusses abgeflossen sein mussten. Eine Möglichkeit für den Verbleib des Wassers ist die kurzfristige Speicherung in Eisstauseen, wie es in Ostdeutschland durch entsprechende Staubeckensedimente nachgewiesen wurde (Eissmann 1994). Solche Sedimente wurden bislang im Untersuchungsgebiet nicht gefunden, so dass ein weiterer Abflussweg für die Schmelz- und Flusswässer in Urstromtälern und subglazialen Rinnen zu suchen ist. Ein solcher Abflussweg ist das Große Bruch, das als West-Ost streichende, 2 bis $3 \mathrm{~km}$ breite und 40 $\mathrm{km}$ lange Talung in 20 bis $30 \mathrm{~km}$ Entfernung vom Harzrand verläuft. Das Große Bruch mündet im Westen ins Okertal und im Osten geht es in den Unterlauf des Bodetals über.

Die Entstehung der Großen Bruch-Rinne ist bislang noch nicht zweifelsfrei geklärt. Eine tektonische Anlage wird ausgeschlossen, da die Rinne die präglazialen Schichten und Strukturen im spitzen Winkel schneidet (FeldmanN et al. 2001, Feldmann 2002). Daher wird für die Rinne eine rein erosive Entstehung angenommen. Der Rinneninhalt besteht von unten nach oben aus lokal auftretendem saalezeitlichen Geschiebemergel, saalezeitlichen Schmelzwassersedimenten, weichselzeitlichen Flusssanden, holozänen Beckenschluffen und Niedermoortorfen (Feldmann et al. 2001). Die Mächtigkeit dieser quartären Talfüllung ist mit 24 bis $60 \mathrm{~m}$ stark schwankend, so dass die Quartärbasis in der Rinne z.T. Übertiefungen aufweist. Nach diesen Befunden wird für die Rinne eine subglaziale Entstehung während der Maximalverbreitung des Drentheeises angenommen (FeldmanN et al. 2001). Nach Vorstellung von Feldmann (2002) flossen mit erosiver Wirkung unter dem Drentheeis unter 
Druck stehende Schmelzwässer nach Westen und vereinigten sich im Bereich der OkertalRinne mit aus Norden kommenden Schmelzwässern. Diese flossen zusammen nach Süden zum Eisrand ab. Von dort erfolgte der Abfluss der Schmelzwässer auf oder unter dem Eisrand parallel zum Harzrand in westliche Richtung (Bombien 1987, Feldmann 2002). Hinweis hierfür gibt eine von Goslar über Astfeld und Langelsheim entlang des Gebirgsfußes verlaufende markante Talung.

Die Große Bruch-Rinne hatte zumindestens im Westteil eine Vorform durch eine fluviatile Talung. Dies deuten MittelterrassensedimentVorkommen des Ilse-Rammelsbachsystems am Ost- und Nord-Rand des Großen Fallsteins an (Feldmann et al. 2001, Weymann 2004). Dagegen kann für den östlichen Teil des Großen Bruchs zwischen Hessendamm und dem Bodetal eine prädrenthezeitliche Vorform eines durchgehenden Flusses oder in der Elster-Kaltzeit angelegtes Urstromtal, wie es von ELsNer (2003) vermutet wurde, sicher ausgeschlossen werden. Gründe hierfür sind das Fehlen von Terrassensedimenten und eindeutigen elsterzeitlichen Schmelzwasserablagerungen.

Nach dem Drenthe-Maximalstand ist die Eismasse abgeschmolzen bzw. zerfallen. Die Abschmelzphasen erfolgten sukzessive, so dass während dieser Zeit der Eisrand durch kleine erneute Vorstöße oszillierte, im weiteren Abschmelzprozess zerriss und so große stagnierende Eismassen zurückließ. Dies ist durch Endmoränen und Kamesablagerungen, die z.T. von Grundmoränen unterlagert werden, dokumentiert (Feldmann 2002). Solche Vorkommen sind in Harzrandnähe zwischen Bad Harzburg und Goslar bzw. im weiteren Verlauf zwischen Astfeld und Langelsheim in Richtung Rhüden zu finden. Das Vorkommen am Tillyberg östlich von Astfeld weist im Liegenden eine 2-3 m mächtige Grundmoräne und darüber $3 \mathrm{~m}$ mächtige glazifluviatile Nachschüttsedimente auf (Feldmann 2002).
Überlagert wird die Abfolge von 8 bis $22 \mathrm{~m}$ mächtigem groben Harzschotter, der von PiLGER (1991) als "Schottersturz" gedeutet wurde. Der grobe Harzschotter weist in diesem und in einem benachbarten Vorkommen einen nordischen Geröllanteil von 7 bis $8 \%$ auf. Diese Vorkommen werden von Feldmann (2002) als Kamesablagerungen gedeutet. Auf dem stagnierenden Eis wurde das Material durch von Süden kommende Harzflüsse transportiert und in Spalten sowie in Kesseln abgelagert. Ein ähnliches Vorkommen ist bei Warnstedt zu finden (Weymann 2004). Hier lagern über einer Grundmoräne $8 \mathrm{~m}$ Kies, der im Geröllbestand wenig nordischen $(5 \%)$ und viel paläozoischen Anteil (91-93\%) aufweist. Der paläozoische Geröllanteil kann dem Einzugsgebiet der Bode zugeordnet werden. Ähnliche Vorkommen mit geringem nordischen Geröllanteil und in der Höhenlage einer Mittelterrasse wurden von Rosenberger \& Altermann (1975) bei Halberstadt sowie von Bombien (1987) östlich der Radau beschrieben und als "Mischsedimente" interpretiert. Dagegen wird das Vorkommen bei Warnstedt von WeYManN (2004) vor allem nach seiner Höhenlage von $45 \mathrm{~m}$ über der heutigen Bode als proximale Schmelzwasserablagerung gedeutet. Der hohe paläozoische Geröllgehalt lässt sich auf Umlagerung älterer Bodesedimente zurückführen. Weiterhin deuten Überschiebungen und Verfaltungen in der Abfolge auf eine nachträgliche glazitektonische Überprägung hin. Daher wird die gesamte Abfolge als Stauchendmoräne gedeutet. Ein weiteres Stauendmoränen-Vorkommen ist bei Abbenrode aufgeschlossen. Hier liegt über den Mittelterrassensedimenten Geschiebemergel, der von einem zweiten, z.T. deformierten Geschiebemergel überlagert wird. Darüber folgen $15 \mathrm{~m}$ mächtige Schmelzwassersedimente, die nach schuppenförmigem Aufbau und Überschiebungen vom nordischen Inlandgletscher glazitektonisch überprägt wurden. Dieser Aufschluss ist mehrmals beschrieben worden und 
wurde zusammenfassend in Feldmann (2002) dargestellt. Feldmann $(1997,2002)$ sieht in dem Vorkommen bei Abbenrode eine eigenständige Eisrandlage und bezeichnet diese als "Abbenroder Randlage". Mit dieser Randlage könnte auch das Stauchendmoränen-Vorkommen bei Warnstedt korreliert werden. Nach Westen lässt sich die "Abbenroder-Randlage" aufgrund steilgestellter Schmelzwassersedimente nördlich des Harlys und weiter im Westen aufgrund der Morphologie am Nordfuß des Salzgitterer Höhenzuges vermuten.

Die nächstjüngere Eisrandlage ist im Untersuchungsgebiet nicht mehr als durchgehende Eisfront rekonstruierbar, sondern durch isolierte Endmoränen-Vorkommen dokumentiert. Ein solches Vorkommen beschrieb Wagenbreth (1970) nördlich von Oschersleben, das er als "Endmoräne von Hornhausen-Druxberge" bezeichnete. $\mathrm{Ob}$ auch das fragwürdige Vorkommen südlich des Großen Bruchs bei Jerxheim zu dieser Randlage gehört, muss offen bleiben (Feldmann 2002). Jüngere Eisvorstöße erreichten das Untersuchungsgebiet nicht mehr. In der darauffolgenden Vereisungsphase, dem jüngeren Drenthe-Stadium (Drenthe 2), stieß das Inlandeis bis nach Leipzig vor und bildete die Petersberger Eisrandlage (Ruske 1964, Feldmann 2002). Dessen Entwässerung im Raum Leipzig-Halle-Bernburg beeinflusste das Untersuchungsgebiet (Ruske 1963, 1964, Feldmann et al. 2001, Feldmann 2002). Danach ist das Schmelzwasser durch das Saaletal bis Bernburg und im weiteren Verlauf über Staßfurt, Oschersleben durch die Talung des Großen Bruchs geflossen. Ab Hornburg nahm das Schmelzwasser seinen Weg durch das Okertal in Richtung Norden zum Allertal. $\mathrm{Zu}$ dieser Zeit wurde die Große Bruch-Rinne noch einmal als Urstromtal reaktiviert (Feldmann 2002). Somit ist ein Teil der glazifluviatilen Rinnenfüllung in diese Zeit zu stellen, wobei es nach geröllpetrographischer Auswertung keine Hinweise auf das Einzugsgebiet der Saale gibt
(Feldmann et al. 2001). Vorstellbar ist, dass bislang nicht nachgewiesene lokale Eisstauseen südöstliche Gerölle zurückgehalten haben.

\subsubsection{Warthe-Stadium}

Während des Warthe-Stadiums herrschten im Untersuchungsgebiet periglaziale Bedingungen. Bombien (1987) hält die geologischen Verhältnisse während dieser Zeit für weitgehend ungeklärt. Er vermutet für diese Zeit eine intensive Erosion, da sich die Harzflüsse nach der drenthezeitlichen Vergletscherung neue Wege nach Norden bahnen mussten. Feldmann (2002) vertritt die Auffassung, dass die großen Täler der Innerste, Oker, Ecker, Ilse und Holtemme bereits während der Drenthehauptvereisung durch subglaziale Erosion angelegt und im Warthe-Stadium bereits von Harzgewässern genutzt wurden. Zudem glaubt FeldmanN (2002) an verschiedenen Stellen im Bereich der Oker, Ecker und Stimmecke nach morphologischen Kriterien lokale Terrassenleisten ausgliedern zu können. Nach ihrer Höhenlage über Vorfluterniveau liegen diese mit 5 bis 8 $m$ zwischen der Höhenlage der Mittel- und Niederterrasse. Aufschlüsse wurden in den Sedimenten bisher nicht gefunden, aber nach Sondierungen handelt es sich um sandigen Kies bis kiesigen Sand, in dem geröllpetrographisch Harzgesteine dominieren. Allerdings konnte keine repräsentative Kiesanalyse ausgewertet werden. Nach diesen Befunden sind die warthestadialen Terrassenleisten nicht eindeutig belegbar, aber unter der Annahme, dass im gesamten Warthe-Stadium hochkaltzeitliches periglaziales Klima herrschte, nicht auszuschließen. 


\subsection{Eem-Warmzeit}

Den derzeitigen zusammenfassenden Untersuchungsstand über eemzeitliche Sedimente und Bildungen im nördlichen Harzvorland liefert FELdmann (2002). Hiernach sind nur wenige solcher Vorkommen im Untersuchungsgebiet bekannt. Hierzu zählen die Eem-Vorkommen bei Isingerode (Rohdenburg \& Meyer 1966) und Aschersleben (Mania 1967). Am Ende der Saale-Kaltzeit wurden die warthestadialen Sedimente erodiert, so dass zu Beginn der EemWarmzeit die Flüsse etwa ihr heutiges Niveau erreichten. Dies deutet der fossile Eem-Boden bei Isingerode an, der nach seiner Höhenlage etwa im heutigen Auenniveau liegt. In dem Vorkommen wird ein Rest einer eemzeitlichen Parabraunerde, der als Bt-Horizont erhalten ist, von einem Bleichhorizont sowie drei $\mathrm{Hu}$ muszonen überlagert (Rohdenburg \& MeYer 1966). Nordwestlich von Aschersleben wurden bei der Bildung einer postdrenthezeitlichen Taldepression über dem Salzrücken des Ascherslebener Sattels u.a. eemzeitliche Seekreide und Mudden abgelagert (Mania 1967). Weitere pedogenetische Anzeichen der Eem-Warmzeit stellen Karbonatzementierungen dar. Solche Zementierungen sind in einem Vorkommen bei Aschersleben aufgeschlossen (WEYMANN 2004). Hier weisen im oberen Bereich der Mittelterrassensedimente, die am Top von Löss überdeckt werden, z.T. starke Kalkzementationen und Konkretionen auf. Wenn auch die Zementationen nicht näher untersucht wurden, so kann von einer beginnenden Zementierung in der Eem-Warmzeit ausgegangen werden, die sich bis ins Holozän fortgesetzt hat. Zu solchen Ergebnissen kam ElbRacht (2002) bei seinen Untersuchungen von karbonatischen Zementationen in pleistozänen Lockersedimenten in Nordwest-Deutschland. Hiernach konnte im Großteil der Vorkommen die Hauptzementationsphase in die Eem-Warmzeit gestellt werden.

\subsection{Weichsel-Kaltzeit}

Während der Weichsel-Kaltzeit erreichten weder die nordischen Inlandgletscher noch deren Schmelzwässer das Untersuchungsgebiet, so dass hier periglaziale Bedingungen vorherrschten. Unter diesen Bedingungen haben sich Löss, fluviatile Niederterrassensedimente und Fließerden abgelagert. Hinzu kommen die typischen periglazialen Prozesse wie Eiskeilbildungen, Kryoturbationen und interstadiale Bodenhorizonten. Von Feldmann (2002) wurden im Weddebach- und im Stimmecketal zwei jungpleistozäne Lössprofile aufgenommen. Unter dem holozänen Boden liegen zwei Nassböden, die durch eine Lössschicht getrennt werden. Darunter folgen ein Verbraunungs- und Verlehmungshorizont bzw. Relikte eines braunen Bodens, der von mächtigem Löss unterlagert wird. Neben den Humuszonen bei Isingerode (Rohdenburg \& Meyer 1966), die in die Altweichselzeit gestellt werden, entsprechen die braunen Böden der Mittelweichsel- und die Nassböden der Jungweichselzeit (FELdmanN 2002). Eine weitere bedeutende weichselzeitliche Ablagerung stellen die in den Flusstälern auftretenden Niederterrassensedimente dar, die als kaltzeitliche Aufschotterung in verwilderten Flusssystemen (braided river) entstanden sind. Nach ihrer Höhenlage liegen diese mit 0 bis 1 $\mathrm{m}$ über Vorfluter in Talauenniveau (BombiEN 1987, WEYMANN 2004). Allerdings weisen Feldmann (2002) und Bombien (1987) darauf hin, dass die bisher auskartierten Niederterrassensedimente im oberen Bereich einen größeren Anteil an holozänem Schotter beinhalten können.

Vielerorts sind im oberen Bereich der Mittelterrassensedimente, die nur von geringmächtigem Löss überdeckt werden, bis zu 2 m tiefe weichselzeitliche Kryoturbationshorizonte ausgebildet. Diese Kryoturbationen weisen damit eine sehr viel größere Dimension auf, als die mittelpleistozänen Formen. Ursache für ihre Bildung 
war der längere periglaziale Zeitraum. Dies gilt auch für die in den Mittelterrassensedimenten oder in Geschiebelehm auftretenden Eiskeile, die im Vergleich zu den älteren die größten Breiten und Tiefen besitzen. In verschiedenen Aufschlüssen werden die Kryoturbationen oder Eiskeile von Fließerden überlagert, die bis 0,8 m mächtig werden können. Die Fließerde kann auf das ausgehende Hochglazial und Spätglazial der Jungweichselzeit eingegrenzt werden (FeLDMANN 2002).

\section{Fazit}

Aus dem nördlichen Harzvorland stellen die Untersuchungsergebnisse der pleistozänen Sedimente ein Bindeglied zu den Ergebnissen aus dem Weser-Leinegebiet (LüTtig 1958, 1960) im Westen und aus dem Saale-Elster-Muldegebiet (Ruske 1964, I 965 , EISSMANN I 975, I 994 , I997, KNOTH 1995) im Osten dar. Insbesondere für den Saale-Komplex und für die WeichselKaltzeit lässt sich aufgrund der vielen Vorkommen die stratigraphische Abfolge rekonstruieren und hieraus eine grobe Klimaentwicklung herleiten. Dennoch bleiben für die pleistozäne Entwicklungsgeschichte eine Menge Fragen offen. Hierzu zählt das Entwässerungsnetz der Schmelzwässer während der Elster- und SaaleKaltzeit. Einen Hinweis hierfür liefern u.a. die Große Bruch- und die Okertal-Rinne, in denen sich eine Entwässerung der Schmelzwässer nach Süden zum damaligen Eisrand andeutet.

Die wenigen im Untersuchungsgebiet verteilten warmzeitlichen Bildungen können nur im stratigraphischen Verband zu Mittelterrassensedimenten datiert werden. Auch die Schmelzwasserablagerungen werden nur aufgrund ihrer Lage zu Mittelterrassensedimenten der jeweiligen Kaltzeit zugeordnet. Somit bekommen im Untersuchungsgebiet die Mittelterrassensedimente für die zeitliche Einordnung pleistozä- ner Sedimente eine wichtige stratigraphische Leitfunktion.

Bislang ungeklärt ist die pleistozäne Erosion und die daraus folgende Flusstalbildung, die zu den markanten Höhenlagen der Terrassensedimente führte. Marriot (1999) führt die Ursache für die quartäre Talerosion u.a. auf tektonische Hebung zurück. Hinweis für postmittelterrassenzeitliche tektonische Hebung liefern nach Feldmann (2002) die markant großen Höhenlagen von Mittelterrassensediment-Vorkommen am Süd- und Ostrand des Großen Fallsteins. Der Große Fallstein bildet eine durch Salzaufstieg bedingte Struktur und führte in diesem Bereich aufgrund junger Hebung zu den außergewöhnlichen Höhenlagen. Zudem liegen der Große Fallstein und die südlich angrenzenden Gebiete im Bereich der Eichsfeld-Altmark-Schwelle, die nach PAUL (1993) seit dem Oberkarbon als Hochgebiet aktiv ist. So werden im Bereich dieser Schwelle im südlichen Harzvorland bei Osterode pleistozäne Flusslaufänderungen auf mittel- und jungpleistozäne Hebung zurückgeführt (JoRDAN 1995). Dagegen sieht Weymann (2004) die große Höhenlage der Mittelterrasse am Großen Fallstein als Folge der verstärkten Erosion durch die postmittelterrassenzeitliche Laufänderung und damit verbundener Laufverkürzung des Ilse-Rammelsbachsystems zur Oker.

Eine weitere Ursache für die Talerosion wird von Feldmann (2002) im Abschmelzen des spätsaalezeitlichen Permafrostbodens gesehen. Hierbei wurden in den Flusstälern warthestadiale Flusssedimente, wie vereinzelte Fundpunkte im Bereich der Oker und Ecker vermuten lassen, weitestgehend ausgeräumt. Nach MARRIOT (1999) kann ein Teil der quartären Talerosion u.a. auf einen Wechsel der Klimabedingungen zurückgeführt werden. Besonders an der Grenze Saale-Kaltzeit/ Eem-Warmzeit bzw. Eem-Warmzeit/WeichselKaltzeit kam es zum Wechsel von sedimentärem $\mathrm{zu}$ erosivem Verhalten eines Flusses (BüDEL 1969, VANDEnBerghe 1993). 
Feldmann (2002) deutet das heutige Flusstalnetz als ein unter dem Drentheeis subglaziär, erosiv anlegtes Rinnensystem, das in der Abschmelzphase des Drentheises wieder Harzgewässer aufnahm. Regional führten nach Bombien (1987) und Weymann (2004) auch mächtige Schmelzwasserablagerungen des saalezeitlichen Inlandeises zu Flusslaufänderungen. Dies hatte z.B. die Laufänderung des Ilse-Rammelsbachsystems zur Folge, als in der Abschmelzphase zwischen Großem Fallstein und Huy der Inlandgletscher lag und so den alten Flussweg nach Norden versperrte (WeYMANN 2004). Hinweise hierfür liefern in diesem Raum mächtige Schmelzwasserablagerungen.

Nach den im Untersuchungsgebiet verbreiteten Sedimenten sowie warmzeitlichen Böden lässt sich eine Aussage über die klimatische Entwicklung für das Pleistozän der Region machen (FeldMann 2002):

Eindeutige Klimaanzeiger ergeben sich erst mit den Ablagerungen der Elster-Kaltzeit (Tab. 1). Zunächst kam es zur Aufschüttung der Oberterrassensedimente, die unter periglazialen Bedingungen geschah. Die anschließende elsterzeitliche Vergletscherung ging mit einer starken Temperaturerniedrigung einher. Die Jahresdurchschnittstemperatur lag im nördlichen Harzvorland weit unter $0^{\circ} \mathrm{C}$ (kontinuierlicher Permafrost).

Die darauffolgende Holstein-Warmzeit war sehr wahrscheinlich etwas wärmer als das Holozän. Der Saale-Komplex begann in der Fuhne-Kaltzeit mit einer Abkühlung. Kryoturbationen und Eiskeile deuten auf Permafrost mit Jahresmitteltemperaturen weit unter $0^{\circ} \mathrm{C}$ und periglaziale Verhältnisse hin. In der folgenden DömnitzWacken-Warmzeit haben mit Jahresmittelschnittstemperaturen bis $10^{\circ} \mathrm{C}$, belegt durch Bodenbildung, interglaziale Klimaverhältnisse geherrscht. Die folgende Abkühlungsphase mit Aufschüttung der Mittelterrassensedimente lief stufenweise mit zwischengeschalteten interstadialen Erwärmungsphasen ab. Die Zeit begann mit dem Aufbau eines Permafrostbodens, angezeigt durch Fließerden und Eiskeile. Durch weitere Abkühlung kam zur Ablagerung der unteren Mittelterrassensedimente. Der darauffolgende Hochflutlehm dokumentiert eine kurzfristige Wiedererwärmung, allerdings herrschten immer noch periglaziale Bedingungen vor. Anzeiger hierfür sind Kryoturbationen. Die anschließende Abkühlung mit Ablagerung der mittleren und oberen Mittelterrassensedimente wurde durch eine kühle interstadiale Zeit mit Kryoturbationen unterbrochen. Im DrentheHochglazial erfolgte die zweite Vergletscherung des nördlichen Harzvorlands. Danach schlossen sich ohne nachweisbare klimatische Unterbrechung die Drenthe 2- und Warthevereisung an, die beide das Harzvorland nicht erreichten.

In der Eem-Warmzeit lagen die Temperaturen zum Klimaoptimum über den maximalen holozänen Werten.

Die Weichsel-Kaltzeit begann mit einer raschen Abkühlung unter $0^{\circ} \mathrm{C}$, worauf Fließerden hinweisen. Danach kam es unter interstadialen Bedingungen zur Bildung von humosen Zonen. Darauf folgende Fließerden zeigen wieder periglaziale Bedingungen an. Im Mittelweichsel führte eine Erwärmung zur Bildung eines braunen Bodens, der anschließend periglazial überprägt wurde. Das Weichsel-Hochglazial zeigt mit Niederterrassensedimenten, Löss und Eiskeilen periglaziale Bedingungen an. Im Spätglazial folgte eine Wiedererwärmung mit kurzen Klimarückschlägen, die zur Bildung von Fließerden führte. Mit dem Holozän begann eine warm-feuchte Klimaentwicklung, die bis heute andauert.

\section{Schriftenverzeichnis}

Bode, A. \& Schroeder, H. (1926): Erläuterung zur Geologischen Karte von Preußen und benachbarten deutschen Landen, Blatt 
Goslar. - 113 S.; Berlin.

Bombien, H. (1983): Untersuchungen zur petrographischen Zusammensetzung und Verteilung glaziärer, periglaziärer und fluviatiler Ablagerungen des Pleistozäns zwischen Langelsheim, Bad Harzburg und Vienenburg (nördliches Harzvorland). - Dipl.-Arb. u. selbst. Geol. Kart. I. Studiengang Geol./ Paläont. Fachber. Erdwiss. Univ. Hannover: 130 S., Hannover [unveröff.].

Bombien, H. (1987): Geologisch-petrographische Untersuchungen zur quartären (frühSaale-zeitlichen) Flußgeschichte im nördlichen Harzvorland. - Mitt. geol. Inst. Univ. Hannover, 26: 131 S.; Hannover.

Christofzik, H. (1983): Untersuchungen zur petrographischen Zusammensetzung und Verteilung glaziärer, periglaziärer und fluviatiler Ablagerungen des Pleistozäns im Raum Vienenburg - Schladen (nördliches Harzvorland). - Dipl.-Arb. u. selbst. Geol. Kart. I. Studiengang Geol./Paläont. Fachber. Erdwiss. Univ. Hannover: 81 S., Hannover. [unveröff.].

BüDEL, J. (1969): Der Eisrinden-Effekt als Motor der Tiefenerosion in der exessiven Talbildungszone. - Würzb. Geogr. Arb., 25: 41 S.; Würzburg.

DAhlgrüN, F. (1929): Beobachtungen über das Diluvium des Unterharzes. - Sitzungsber. geol. L.-Anst, 4: 30-38; Berlin.

Duphorn, K. (1968): Ist der Ostharz im Pleistozän vergletschert gewesen? - Eiszeitalter u. Gegenwart, 19: 164-174; Öhringen/Württ.

Duphorn, K. (1976): Quartär. - In: Hinze, C.: Geologische Karte von Niedersachsen 1: 25.000, Erläuterungen zu Blatt Seesen Nr. 4127: 52-61; Hannover.

Eissmann, L. (1975): Das Quartär der Leipziger Tieflandsbucht und angrenzender Gebiete um Saale und Elbe - Modell einer Landschaftsentwicklung am Rand der europäischen Kontinentalvereisung. - Schriftr. geol. Wiss., 2: 263 S.; Berlin.
Eissmann, L. (1994): Grundzüge der Quartärgeologie Mitteldeutschlands (Sachsen, Sachsen-Anhalt, Südbrandenburg, Thüringen). - Altenburger nat. wiss. Forsch., 7, (DEUQUA-Tagung Leipzig 1994): 55-135; Altenburg.

Eissmann, L. (1997): Das quartäre Eiszeitalter in Sachsen und Nordostthüringen. - Altenburger nat. wiss. Forsch., 8: 98 S. + Beil.Bd.; Altenburg.

Elbracht, J. (2002): Karbonatische Zementation pleistzäner Lockersedimente NWDeutschlands. - Diss. Univ. Hannover: 111 S.; Hannover.

Elsner, H. (2003): Verbreitung und Ausbildung Ester-zeitlicher Ablagerungen zwischen Elm und Flechtinger Höhenzug. - Eiszeitalter u. Gegenwart, 52: 91-116; Hannover.

Feldmann, L. (1997): Drenthezeitliche Eisrandlagen zwischen Harz und Allertal. - Z. geol. Wiss., 25 (1/2): 181-190; Berlin.

Feldmann, L. (2002): Das Quartär zwischen Harz und Allertal mit einem Beitrag zur Landschaftsgeschichte im Tertiär. - Clausthaler Geowissenschaften, 1: 149 S.; ClausthalZellerfeld.

Feldmann, L. \& Groetzner, J.-P. (1998): Quartär im Harzvorland - Einführung in das Exkursionsgebiet. - In: Feldmann, L. \& Meyer, K.-D. (Hrsg.): Quartär in Niedersachsen. - Exk.-Führer DEUQUA Hannover, Exkursion B: 38-42; Hannover.

Feldmann, L., Groetzner, J.-P. \& Weymann, H.-J. (2001): Zur pleistozänen Geschichte des "Großen Bruch" im nördlichen Harzvorland. - Geol. Beitr. Hannover, 2: 127 137; Hannover [Henningsen-Festschrift].

Groetzner, J.-P. (1998): Gletschertöpfe im Huy. - In: Feldmann, L. \& Meyer, K.-D. (Hrsg.): Quartär in Niedersachsen. - Exk.Führer DEUQUA Hannover, Exkursion B: 79-80; Hannover.

Groetzner, J.-P. \& Weymann, H.-J. (1998): Petrographie und Strukturen Saale-zeitlicher 
Sedimente bei Großalsleben. - In: FeldMANN, L. \& Meyer, K.-D. (Hrsg.): Quartär in Niedersachsen. - Exk.-Führer DEUQUA Hannover, Exkursion B: 75-78; Hannover.

Groetzner, J.-P. \& Winter, S. (1998): Das Quartärprofil von Hoym. - In: Feldmann, L. \& Meyer, K.-D. (Hrsg.): Quartär in Niedersachsen. - Exk.-Führer DEUQUA Hannover, Exkursion B: 71-74; Hannover.

Grupe, O. (1921): Ausdehnung der ältesten (drittletzten) Vereisung in Mitteldeutschland. - Jb. preuß. geol. L.-Anst., 42: 161 174; Berlin.

Hinze, C., Jordan, H., Knoth, W., Kriebel, U. \& Martiklos, G. (1998): Geologische Karte Harz 1:100.000. - 1. Kt.; Halle (GLA-LSA u. NLfB).

Hoffmann, K. \& Meyer, K.-D. (1997): Leitgeschiebezählungen von elster- und saalezeitlichen Ablagerungen aus Sachsen, SachsenAnhalt und dem östlichen Niedersachsen. Leipziger Geowiss., 5: 115-128; Leipzig [Eißmann-Festschrift].

Höfle, H.-Ch. (1991): Über die innere Struktur und die stratigraphische Stellung mehrerer Endmoränenwälle im Bereich der Nordheide bis östlich Lüneburg. - Geol. Jb., A 126: 151-169; Hannover.

Jordan, H. (1995): Quartäre Tektonik und Gipskarst am Südharz, Niedersachsen. - Beitr. z. Geol. v. Thüringen, N. F., 2: 7596; Jena.

Kaltwang, J. (1992): Die pleistozäne Vereisungsgrenze im südlichen Niedersachsen und im östlichen Westfalen. - Mitt. geol. Inst. Univ. Hannover, 33: 161 S.; Hannover.

Knoth, W. (1964): Zur Kenntnis der pleistozänen Mittelterrassen der Saale und Mulde nördlich Halle. - Geologie, 13: 599-616; Berlin.

Knoth, W. (1995): Sachsen-Anhalt. - In: Benda, L. (Hrsg): Das Quartär Deutschlands: 148-170; Berlin.

Koenigswald, W. von (1972): Sudmerberg-2, eine Fauna des frühen Mittelpleistozäns aus dem Harz. - N. Jb. Geol. Paläont., Abh., 141, (2): 194-221; Stuttgart.

Koenigswald, W. von \& Heinrich, W.-D. (1998): Säugetierstratigraphische Gliederung im Mittelpleistozäns in Korrelation zu den nordischen Verisungen. - In: FeLDMANN, L., Benda, L. \& Look, E.-R. (Hrsg.): 50 Jahre DEUQUA, 50 Jahre Forschung in Eiszeitalter und Gegenwart. - Kurzfass. Vorträge u. Poster, DEUQUA-Tagung Hannover 1998: 37-38; Hannover.

Look, E.-R. (1984): Geologische Wanderkarte 1:100.000. - Hannover (NLfB).

Ludwig, A. (1958): Beobachtungen im Pleistozän des nordöstlichen Harzvorlandes. - Geologie, 7: 769-793; Berlin.

LütтіG, G. (1954): Alt- und mittelpleistozäne Eisrandlagen zwischen Harz und Weser. - Geol. Jb., 70: 43-125; Hannover.

LütTIG, G. (1958): Heisterbergphase und Vollgliederung des Drenthe-Stadiums. - Geol. Jb., 75: 419-430; Hannover.

LÜTTIG, G. (1960): Neue Ergebnisse quartärgeologischer Forschung im Raume AlfeldHameln-Elze. - Geol. Jb., 77: 337-390; Hannover.

LütTIG, G. (1964): Prinzipielles zur QuartärStratigraphie. - Geol. Jb., 82:177-202; Hannover.

Mania, D. (1967): Das Quartär der Ascherslebener Depression im Harzvorland. - Hercynia, 4: 51-82; Leipzig.

Marriott, S. B. (1999): The use of models in the interpretation of the effects of base-level change on alluvial architecture. - Spec. Pupl. int. Ass. Sediment., 28: 271-281 [Ort unbekannt].

Paul, J. (1993): Anatomie und Entwicklung eines permo-triassischen Hochgebietes: die Eichsfeld-Altmark-Schwelle. - Geol. Jb., A 131: 197-218; Hannover.

Pilger, A. (1991) mit Beiträgen von МоснA, P., Petzold, B. \& Rösler, A.: Die nordi- 
schen Gletscher am nordwestlichen Harzrand und ihre Stauseen. - Clausthaler geol. Abh., 48: 159 S.; Köln.

Preul, F. (1968): Die Subrosion am Salzstock von Salzgitter-Lebenstedt. - Geol. Jb., 85: 809-816; Hannover.

Rausch, M. (1977): Fluß-, Schmelzwasser- und Solifluktionsablagerungen im Terrassengebiet der Leine und Innerste - ein Beitrag zur pleistozänen Flußgeschichte Südniedersachsens. - Mitt. geol. Inst. Univ. Hannover, 14: 84 S.; Hannover.

Rohdenburg, H. \& Meyer, B. (1966): Zur Feinstratigraphie und Paläopedologie des Jungpleistozäns nach Untersuchungen an südniedersächsischen und nordhessischen Lößprofilen. - Mitt. dt. bodenkdl. Ges., 5: 1-135; Göttingen.

Rosenberger, G. \& Altermann, M. (1975): Ein Pleistozänprofil aus dem nördlichen Harzvorland. - Z. geol. Wiss., 3: $1617-$ 1621; Berlin.

Ruske, R. (1963): Zur Entstehung des Gewässernetzes in der Umgebung von Halle/Saale. - Hercynia. N. F., 1: 40-50; Leipzig.

Ruske, R. (1964): Das Pleistozän zwischen Halle (a.d.S.), Bernburg und Dessau. - Geologie, 13: 570-597; Berlin.

Ruske, R. (1965): Zur Gliederung der Holstein- und Saalezeit im östlichen Harzvorland. - Eiszeitalter u. Gegenwart, 16: 88-96; Öhringen/Württ.

Schroeder, H. (1919): Süßwasserkalke, Hercynschotter und Glazialbildungen am Huy und Fallstein. - Jb. preuß. geol. L.-Anst., 40 (2): 1-45; Berlin [1922].

Schroeder, H. (1930): Geologische Übersichtskarte der subherzynen Kreidemulde 1: 100.000. - 1 Kt.; Berlin.

Spreitzer, H. (1931): Die Talgeschichte und Oberflächengestaltung im Flußgebiet der Innerste. - Jb. geogr. Ges. Hannover, 1931: 115 S.; Hannover.

Steiner, W. (1957): Spuren der Eiszeit im Huy.-
Wissen u. Leben, 12: 923-925; Stuttgart.

Traupe, J. (1990): Hydrogeologische und ingenieurgeologische Untersuchungen der Deponie Leinde der Stahlwerke Peine-Salzgitter AG bei Leinde, Südost-Niedersachsen. - Dipl.-Arb. TU Clausthal: 104 S., 133 Anl.; Clausthal-Zellerfeld [unveröff.].

Urban, B. (1991): Zusammenfassung biostratigraphischer Ergebnisse holstein- und saalezeitlicher Vorkommen im Tagebau Schöningen, Ldkrs. Helmstedt. - Sonderveröff. geol. Inst. Univ. Köln, 82: 329-342; Köln.

VAndenberghe, J. (1993): Changing fluvial processes under changing periglacial conditions. - Z. f. Geomorph N. F., Suppl.-Bd. 88: 17-28; Berlin, Stuttgart.

Wagenbreth, O. (1970): Beobachtungen und Probleme im Quartär des Salzsattels von Staßfurt - Egeln - Oschersleben und seiner Randsenken. - Geologie, 19: 412-433; Berlin.

Weissermel, W. (1926): Erläuterungen zur Geologischen Karte von Preußen und benachbarten deutschen Ländern, Bl. Wegeleben. -54 S.; Berlin.

Weissermel, W. (1930): Zur Stratigraphie und Tektonik des östlichen Teiles der Subhercynen Mulde und ihrer nordöstlichen Nachbargebiete: I. Das Diluvium und seine Stellung im norddeutschen Gesamtdiluvium. - Abh. preuß. geol. L.-Anst., N.F., 125: 93 S.; Berlin.

Weissermel, W., Grupe, O., Dahlgrün, F. \& Schriel, W. (1932): Zum Problem des Harzranddiluviums. - Z. dt. geol. Ges., 84: 173-192; Berlin.

Weymann, H.-J. (2004): Die mittelpleistozäne Flußentwicklung im nordöstlichen Harzvorland - Petrographie, Terrassenstratigraphie. Geol. Beitr. Hannover, 6: 116 S.; Hannover. Woldstedt, P. (1928): Über eine InnersteTerrasse zwischen Derneburg und Broistedt. - Jber. niedersächs. geol. Ver., 21: 1-9; Hannover. 